regions of chromosomes such as the centromere and telomere in cattle, goat and horse; centromere and " secondary constriction" in pig; satellite in cat. However, polymorphism in occurrence of $\mathrm{N}$ bands was observed.

Influence of the $\mathrm{NaH}_{2} \mathrm{PO}_{4}$ incubation on the discovering of $\mathrm{N}$ bands in the fresh and old slides was observed. Staining procedure for $\mathrm{C}$ banding has been used for the comparison of results.

\title{
Frequency and source of chromosome abnormalities in chick embryos
}

\section{N. S. FECHHEIMER}

$$
\begin{array}{r}
\text { Dairy Science Department, The Ohio State University, } \\
\text { Columbus, Ohio } 43210 \text { (U.S.A.) }
\end{array}
$$

In a series of nine studies, $825^{8}$ chicken embryos have been examined for the occurrence of chromosomal abnormalities. Eggs were incubated for only 16 to 18 hours before the embryos, in the primitive streak stage, were removed. Preparations for karyological examination were made from cell suspensions of each embryo. The overall incidence of embryos with aberrations was $49 \mathrm{p}$. I, ooo but there were large and significant differences between stocks of broilertype (BR) and Leghorn-type (LG). BR contained IO2 P. I ooo, LG contained I4.I p. rooo and embryos from crosses between the two contained $46 \mathrm{p}$. Iooo. The most frequently occuring types of abnormalities were haploidy (including haploid-diploid chimerics), polyploidy, diploid-tetraploid mosaics and pure aneuploidy. Their incidences per $I, 000$ in $B L, L G$ and crosses respectively were 54,3 , 19 for haploidy; $21,6,9$ for polyploidy; 16, I, 5 for diploid-tetraploid mosaics; 6,3 , and 9 for aneuploidy. The parental source of each of the primary types of abnormalities has been determined and the place in the reproductive cycle where errors occur giving rise to each has been established. 